health, is another indication that the museum has been informed by current debates on the history of science and medicine.

Mental Health and Powick Asylum make up one of the six featured areas of the exhibition. The inclusion of the history of this local asylum through brief details of individuals who were inmates, interspersed with photographs of staff and patients, serves to humanise those who were defined as insane. This section brings into the open the experiences of those who were simultaneously protected and hidden away from the rest of society in asylums. However, once again, interpretations which focus on individuals leave limited space for debate and discussion about the social construction of mental illness or the social, cultural and political structures of power which framed ideas of sanity and the treatment of those whose behaviour was deemed not to be 'normal'. In the interplay between past and present, that characterises much popular history, the section on mental institutions is framed by an explanation of the taboos that surround mental illness in contemporary Britain. Stephen Fry is presented as an example of a television celebrity whose openness about his own bi-polar disorder has challenged popular perceptions. Indeed, controversy is generally reserved for the present; visitors are encouraged to engage with ethical debates through a 'Debating Space', where opinions are invited on current ethical issues, such as assisted suicide. It is to be hoped that this museum will also encourage further public engagement with the history of science, some of which will be at the larger George Marshall Museum nearby.

Maggie Andrews

University of Worcester, UK

doi:10.1017/mdh.2012.87

\title{
Canada Science and Technology Museum, Ottawa, Canada
}

Technology exerts a constant presence in our daily lives, involving us at every moment in a lengthy and complex narrative of scientific progress. Despite our dependence on relatively recent technological advances and changes, it can be easy to lose sight of our place in this narrative. The Canada Science and Technology Museum works to reacquaint us with the foundations of the technology that now runs much of our world. The museum places the contents of its collection in their scientific and historical context, allowing visitors without a background in the history of science and technology to draw their own conclusions about the significance of the physical materials before them and their relation to the contemporary experience of technology in everyday life.

The permanent exhibit 'Connexions: The Plugged-in World of Communications' skillfully demonstrates this integration of artefact and context, past and present. Rather than simply presenting its wide array of nineteenth- and twentieth-century telephones, radios, and television sets as curious relics of a foreign past, the exhibit continually encourages visitors to view the material contents of the collection through the eyes of the past, with a focus on the experience of the average Canadian living in these centuries. The visitor does not merely observe the exhibit's collection of antique radios through the dissociating barrier of a glass case; instead, he or she can relax in a miniature furnished sitting room to listen to a radio from the 1920s play audio recordings of popular songs of the era. The written descriptions accompanying the collection do not merely identify 
the artefacts in question: they provide insight into the way ordinary people would have used them, and prompt viewers to draw 'connexions' of their own between past and present. Likewise, the extensive collection of Canadian inventions displayed in 'Innovation Canada' is given a frame of reference in a series of textual descriptions explaining the 'idea, innovation, and impact' of each artefact, allowing the casual visitor to appreciate the perhaps visually unimpressive electron microscope, electron wheelchair, and Theratron Junior radiotherapy unit for their significance in the context of twentieth-century medicine. In contrast, 'Energy: Power to Choose', an exhaustive examination of energy use in Canada which raises many questions about the sustainability and reliability of various energy sources, focuses more heavily than the other exhibits on pure textual exposition and leaves the viewer to collate and interpret the information thus presented in an attempt to answer the questions surrounding the controversial issue of energy.

The same attention to matters of historical context and the common experience is equally apparent in the museum's temporary exhibits. In attempting to identify the factors that make a car truly 'Canadian', the exhibit 'In Search of the Canadian Car' complements its diverse selection of motor vehicles with comprehensive textual descriptions and multimedia screens that allow viewers to browse a series of visual and film images, including details of the automobiles on display and advertisements of various eras directed towards the Canadian automotive market. The exhibit provides several perspectives on the Canadian car, focusing at different points on choice, design, manufacturing, and marketing. Ultimately, however, it leaves the responsibility of interpretation to the viewer: computers at each end of the exhibit allow visitors to record their answers to the question, 'What makes a car Canadian?'.

Two minor temporary exhibits near the rear of the museum expertly trace the significance of medical technologies through history. One of these displays examines the first biomimetic cornea created by Dr May Griffith at the Ottawa Hospital Research Institute from recombinant human collagen. The case containing this synthetic cornea is juxtaposed with a display case on 'Artificial Eye Making in Its Various Stages' from the mid-1920s, which recreates the process of fashioning a glass eye through physical artefacts illustrating each stage of the procedure. Likewise, a collection of tools used for eye surgery in the early twentieth century are set side-by-side with a case filled with instruments used by ocular surgeons today. This simple, visually attractive display ably compares technology of the past and present to tell a story about ocular surgery throughout medical history. The second display, entitled 'Braille: Knowledge at Your Fingertips', emphasises experiential learning as a way of relating to the past. This highly interactive exhibit guides the visitor through a collection of writing implements, timepieces, calculators, and reading materials dating from the 1940s to the present by providing 'hands-on' versions of each artefact in order to give the viewer a more immediate sense of how Braille functions in practice.

The museum boasts a rich and varied collection of artefacts which together make up a fascinating picture of the history of Canadian science. However, the true strength of the collection lies in its presentation, which elevates the contents from objects, the importance of which is obvious only to the expert, to elements of a story in which we are all involved. A constant attention to contextualising science and technology and a continual emphasis on the experience of technology by average people sets the Canada Science and Technology Museum apart. The museum challenges its visitors not merely 
to see these artefacts, but to use them to examine the everyday experience of science and technology in the light of a complex and interesting past.

Rachel Fulton

Clarkson University, USA 